\title{
ASSISTÊNCIA DE ENFERMAGEM AO PORTADOR DE ALTERAÇÕES NA INTEGRIDADE CUTÂNEA: UM RELATO DE EXPERIÊNCIA DE ENSINO-APRENDIZAGEM
}

\author{
NURSING ASISTENCE TO THE BEARER OF ALTERATIONS \\ IN THE CUTANEOUS INTEGRITY: \\ A LEARNING EDUCATION EXPERIENCE ACCOUNT
}

\author{
ASISTENCIA DE ENFERMERÍA AL PORTADOR DE ALTERACIONES \\ EN LA INTEGRIDAD CUTÁNEA: \\ UN RELATO DE EXPERIENCIA DE ENSEÑANZA-APRENDIZAGE
}

\author{
Maria José Sanches Marin* \\ Elaine Morelato Vilela* \\ Elisabete Takeda** \\ lone Ferreira Santos ${ }^{* *}$
}

Marin MJS, Vilela EM, Takeda E, Santos IF. Assistência de enfermagem ao portador de alterações na integridade cutânea: um relato de experiência de ensino-aprendizagem. Rev Esc Enferm USP 2002; 36(4): 338-44.

\section{RESUMO}

o Curso de Enfermagem da Faculdade de Medicina de Marilia, vem empenhando-se na construção do Currículo Integrado, utilizando-se da metodologia problematizadora. No presente estudo, os autores apresentam os desempenhos esperados dos estudantes e a seqüência de atividades construida para o ensino dos cuidados de enfermagem ao adulto e idoso portador de alteração da integridade cutânea, a qual permite ao aluno implementar este conhecimento em sua realidade prática. No decorrer das atividades constata-se que tal desafio tem representado um avanço no processo de ensino e aprendizagem, no entanto, apontam-se algumas dificuldades a serem superadas.

PALAVRAS-ChAVE: Currículo. Ensino. Pele. Cicatrização de feridas. Cuidados de enfermagem.

\section{ABSTRACT}

The Nursing Course at the Medicine College in Marilia, has been making every efforts to create the Integrate Curiculum, making use of the questionable methodology. In this study, the authors present the student' expected performances and the sequency of activities creat to teach the precautions of Nursing for the adult and elder people taking away some changes na the cutaneous integrity, that makes the student implement the konowlege. During the activities it was proved that this kind of challenge has showed a progress in the teachin and learning process, but there are some difficulties to be conquered.

KEYWORDS: Curriculum. Teaching. Skin. Wound healing. Nursing care.

\section{RESUMEN}

El Curso de Enfermería de la Facultad de Medicina de Marilia se está empeñando en la construcción de un curriculun integrado, utilizándose de la metodologia problemática. En este estudio, los autores presentan el desarrollo esperado de los estudiantes y la secuencia de actividades construida para la enseñanza de los cuidados de enfermería al adulto y al mayor portador de alteración a la integridad cutánea, la cual permite que el alumno aplique este conocimiento a su realidad práctica. En el transcurso de las actividades se nota que dicho desafio representa un avance en el proceso de enseñanza y aprendizage, pero, algunas dificultades son apuntadas y deben ser superadas.

PALABRAS-CLAVE: Curriculum. Enseñanza. Piel. Cicatrizacion de heridas. Atención de enfermería.

Doutora em Enfermagem e Docente da Disciplina de Enfermagem em Saúde Coletiva do Curso de Enfermagem da Faculdade de Medicina de Marilia.

** Doutoranda do Programa de Pós- graduação em Enfermagem Fundamental da EERP- USP e Docente da Disciplina de Enfermagem Clínica do Curso de Enfermagem da Faculdade de Medicina de Marília.

*** Doutora em Enfermagem e Docente da Disciplina de Enfermagem Clínica do Curso de Enfermagem da Faculdade de Medicina de Marília. 


\section{INTRODUÇÃO}

Os docentes do Curso de Enfermagem da Faculdade de Medicina de Marília (FAMEMA) deram início, em 1993, a um processo de revisão do currículo de graduação e da proposta pedagógica até então adotados. Isto ocorreu pois, analisando o programa de ensino até então adotado, observou-se as seguintes características: a) predomínio do ensino voltado para a área hospitalar e para o desenvolvimento de procedimentos; b) centrado no professor, de forma a não valorizar o conhecimento do aluno; c) desarticulação do perfil epidemiológico regional; d) proposta educacional concebida como reprodutora acrítica da estrutura social.

Esse movimento de revisão do modelo pedagógico foi impulsionado pelas propostas do ideário UNI (Uma Nova Iniciativa), financiado pela Fundação Kellog, o qual tem como pressuposto básico, o efetivo envolvimento dos atores da academia, dos serviços de saúde e da comunidade. Objetiva-se com isso implementar um modelo de educação para os acadêmicos da área da saúde alicerçado nos sistemas locais, em que se busca a participação da comunidade nas decisões relativas ao setor saúde. Ou seja, propõe-se construir um modelo formador de recursos humanos em saúde que atenda ao perfil epidemiológico da população e com a participação $\operatorname{dessa}^{(1)}$.

O processo de revisão curricular se deu mediante o desenvolvimento de vários cursos de capacitação pedagógica, voltados para os docentes do Curso de Enfermagem, os quais entenderam ser a proposta de currículo integrado a que parecia mais próxima de atingir o ideário em questão.

Currículo integrado é definido como um plano pedagógico e sua correspondente organização institucional que articulam dinamicamente trabalho e ensino, prática e teoria, ensino e comunidade. Não só as relações entre trabalho e ensino mas também aquelas entre os problemas e suas hipóteses de solução devem ter sempre, como pano de fundo, as características sócio-culturais do meio em que esse processo se desenvolve(2)

O grupo de docentes entendeu, então, o currículo como sendo a totalidade das situações de ensino-aprendizagem, planejadas intencionalmente pelo coletivo da escola, situações essas que proporcionem experiências direcionadas para $\mathrm{o}$ alcance dos objetivos educacionais da mesma(3)

Tal proposta, no entanto, representou um desafio, principalmente por não existirem "receitas" padronizadas e por depender da reflexão e da criatividade dos envolvidos. Assim é que, em março de 1996, iniciou-se um trabalho de assessoria com o objetivo de ajudar os docentes do curso a responder questões suscitadas naquele momento.
A elaboração do novo currículo do Curso de Enfermagem teve início em 1997 e, desde então, privilegia a integração dos conteúdos e áreas de conhecimento, bem como a utilização da metodologia problematizadora.

Delinearam-se, inicialmente, os principios filosóficos que norteariam o desenvolvimento do currículo, incluindo os conceitos de enfermagem como prática socialmente determinada; de homem como ser capaz de agir e modificar a realidade; de estrutura social constituída pelas relações de poder; e de processo saúde/doença determinado pelo trabalho e formas de vida das pessoas. Esses conceitos são construídos a partir do perfil epidemiológico da região, visto que cabe ao profissional enfermeiro atuar de forma a modificá-los em sua área de atuação(3)

Assim, o enfermeiro a ser formado pelo Curso de Enfermagem da FAMEMA deve ser capaz de(3):

- trabalhar em equipes multiprofissionais e interdisciplinares;

- prestar cuidados de enfermagem;

- ter visão crítica da estrutura social;

- gerenciar a assistência de enfermagem e os serviços de saúde;

- buscar sua constante capacitação e atualização;

- ser capaz de realizar pesquisas.

Para atingir esse perfil, é necessário que o estudante apreenda a história do homem e a relacione com o processo saúde doença e o processo de cuidar; apreenda e aplique os valores politicos e éticos da profissão; tenha conhecimentos e habilidades para desenvolver o processo de cuidar; apreenda e aplique princípios de metodologia científica com a finalidade de solucionar os problemas da prática; desenvolva a capacidade de trabalhar em grupo, de gerenciar a assistência de enfermagem e os serviços de saúde, de valorizar a busca constante de conhecimento e analisar criticamente a realidade social, para identificar problemas e intervir de forma a transformar o perfil epidemiológico(3)

\section{A METODOLOGIA PROBLEMATIZADORA}

A apreensão e utilização da metodologia problematizadora também resultaram dos conhecimentos adquiridos e dos momentos de reflexão do grupo de docentes durante os cursos de capacitação pedagógica.

O método da problematização parte do princípio de que, em um mundo de mudanças rápidas, o importante não são os conhecimentos ou idéias nem os compromissos corretos e fáceis que se esperam, mas sim o aumento da capacidade de percepção da 
transformação social para detectar os problemas reais e buscar para eles soluções originais e criativas ${ }^{(4)}$.

Nesse sentido, a metodologia problematizadora propõe cinco passos a serem seguidos ${ }^{(4)}$ :

$1^{\circ}$ passo: os alunos observam a realidade em si com seus próprios olhos. Quando isso não é possível, utilizam-se os meios audiovisuais que permitem trazer a realidade até o aluno;

$2^{\circ}$ passo: os alunos separam, do que foi observado, o que é verdadeiramente importante do que é superficial;

$3^{\circ}$ passo: é o momento da teorização do problema, onde se pergunta o por quê dos

fatos observados;

$4^{\circ}$ passo: formulam-se as hipóteses das soluções em estudo;

$5^{\circ}$ passo: os alunos praticam e fixam as soluções que o grupo encontrou e elegem as mais viáveis e aplicáveis.

Para representar o método da problematização, Charles Maguerês idealizou o método do arco o que orienta a escolha e o uso dos recursos multisensoriais e está demonstrado no diagrama abaixo .

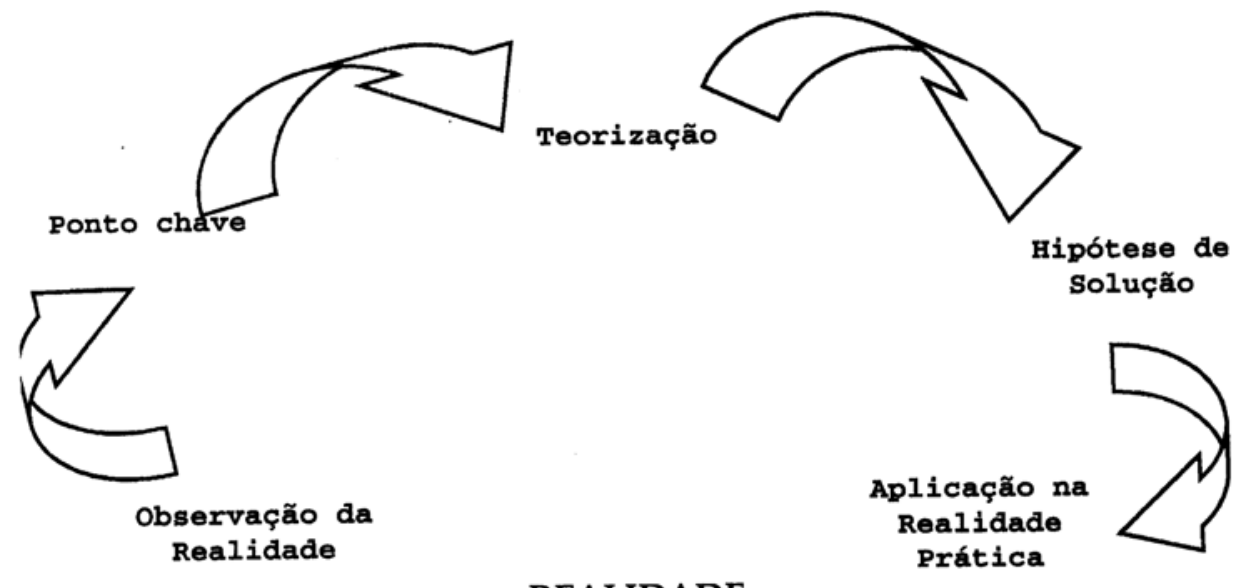

REALIDADE

Fonte: Diaz Bordenave J, Pereira AM. Estratégias de ensino aprendizagem. 134. ed., Petropólis: Vozes; 1993. P 50

Trabalhar nessa direção implica favorecer situações de ensino-aprendizagem contextualizadas, apresentando os novos conteúdos, potencialmente significativos, de forma articulada, com coerência lógica, considerando o conhecimento trazido pelos próprios alunos. A partir daí, constrói-se a interação entre os conhecimentos já presentes na estrutura cognitiva do aluno e as novas informações.

Para efetivação deste método de ensino e obtenção de aprendizagem significativa, é preciso que o estudante reconheça os conteúdos como problemas. Problematizar é o ato de buscar relacionar um novo conjunto de informações à estrutura cognitiva do estudante. O problema, no âmbito prático ou teórico, caracteriza uma situação que envolve múltiplas possibilidades ou alternativas para sua solução. O problema pede uma solução que envolva espírito crítico, reflexão, planejamento e informação para que se possa solucioná-lo, ou seja, envolve o desenvolvimento das competências expressas nos objetivos educacionais ${ }^{(3)}$

\section{A CONSTRUÇÃO DO CURRÍCULO INTEGRADO}

Os docentes do Curso de Enfermagem da FAMEMA, após delinearem os principios gerais a serem seguidos na construção do currículo integrado, elaboraram uma classificação dos conhecimentos necessários denominada de "rede explicativa", em que os principios gerais (conceitos chaves) deram origem às Unidades Educacionais, distribuídas nas quatro séries que compõem o curso, conforme demonstrado no Quadro I.

Assim, deixam de existir as disciplinas tradicionais, substituidas pelas Unidades Educacionais, em que os conteúdos são desenvolvidos, de forma integrada, em seqüências de atividades contextualizadas com a realidade prática vivenciada pelo aluno.

As Unidades Educacionais descrevem o propósito, os objetivos, os desempenhos que os estudantes deverão desenvolver, a seqüência de atividades a serem seguidas tanto pelo aluno como pelo professor, bem como a forma do processo de avaliação. 
Diante da lógica proposta, o sujeito apropria-se dos conhecimentos que sustentam a prática da enfermagem, a partir da reflexão sobre a mesma., o que permite identificar o recorte de conhecimento ou conceito chave que fundamenta o fazer. Os conceitos-chaves, por sua vez, dão origem à Unidade Educacional, na qual os conteúdos de ensino são trabalhados de forma a articulada com a prática e obedecendo a hierarquia da estrutura do conhecimento em questão, ou seja, parte-se dos conceitos mais amplos para os mais específicos. Dessa forma, procura- sistematizar a ação pedagógica de modo que o educando chegue a integrar seus conhecimentos, evitando a rotinização técnica e acúmulo de informações soltas.

Diante do exposto, acrescente-se que o presente estudo se propõe a relatar a experiência .de ensino-aprendizagem da assistência de enfermagem ao adulto e idoso portador de alterações da integridade cutânea, no currículo integrado e através da metodologia problematizadora.

\section{RELATANDO A EXPERIÊNCIA DE ENSI- NO DA ASSISTÊNCIA DE ENFERMAGEM AO ADULTO E IDOSO COM ALTERAÇÕES NA INTEGRIDADE CUTÂNEA}

Ao considerar o currículo integrado, desenvolvido conforme a metodologia problematizadora, o conteúdo deve ser ensinado de forma contextualizada com a realidade de atuação. Desta forma, a assistência de enfermagem ao adulto e ao idoso com alterações da integridade cutânea é conteúdo a ser desenvolvido na Unidade Educacional de saúde do adulto e do idoso, que acontece no segundo semestre da segunda série, conforme o Quadro I. Nessa ocasião, o aluno atua em Unidade Básica de Saúde e tem oportunidade de contato com pessoas portadoras desse agravo no estado de saúde.

Quadro I - Distribuição das séries de acordo com as respectivas Unidades Educacionais e conceitos chaves

\begin{tabular}{|c|c|c|}
\hline SÉRIE & UNIDADE & CONCEITO CHAVE \\
\hline \multirow{6}{*}{$\begin{array}{r}1^{\circ} \\
\text { serie }\end{array}$} & Unidade 1 - Saúde e Sociedade & Homem/sociedade, modo de produção e reprodução social \\
\hline & Unidade 2 - Trabalho em Saúde & Processo de trabalho em enfermagem \\
\hline & Unidade 3 - Realidade e Saúde & Processo saúde doença \\
\hline & Unidade 4 - Produção social da saúde & Práticas sanitárias da família, concepção de família \\
\hline & Unidade 5 - Urgência/emergência pré- & Cuidado ao paciente com risco de vida \\
\hline & Unidade 6 - Interação comunitária" & \\
\hline \multirow{6}{*}{$\begin{array}{r}2^{\circ} \\
\text { serie }\end{array}$} & Unidade 7 - Avaliação do estado de saúde do & Avaliação do estado de saúde do indivíduo \\
\hline & Unidade 8 - Saúde da criança & Criança inserida na sociedade e na família; avaliação da saúde \\
\hline & Unidade 9 - Saúde do adolescente & Adolescente inserido na sociedade e na família; avaliação da \\
\hline & Unidade $\mathbf{1 0}$ e 11 - Saúde do adulto e idoso & 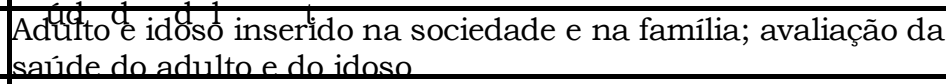 \\
\hline & $\begin{array}{l}\text { Unidade } 12 \text { - Saúde da mulher no ciclo } \\
\text { gravídico-puerperal }\end{array}$ & $\begin{array}{l}\text { Gestante/puérpera inserida na sociedade e na família; } \\
\text { avaliação da saúde gestante/puérpera }\end{array}$ \\
\hline & Unidade 13 - interação comunitária* & \\
\hline \multirow[t]{6}{*}{$\begin{array}{r}3^{\circ} \\
\text { serie }\end{array}$} & $\begin{array}{l}\text { Unidade } 14 \text { - Organização e processo de } \\
\text { trabalho no hospital }\end{array}$ & Organização do trabalho no hospital \\
\hline & Unidade 15 - Cuidado ao adulto hospitalizado & Cuidado ao indivíduo adulto em situações clínicas/cirúrgicas \\
\hline & $\begin{array}{l}\text { Unidade } 16 \text { - Urgência/emergência intra- } \\
\text { hospitalar }\end{array}$ & Cuidado ao paciente com risco de vida \\
\hline & $\begin{array}{l}\text { Unidade } 17 \text { - Cuidado à mulher hospitalizada } \\
\text { em situacones }\end{array}$ & Cuidados à mulher em situações clínicas/cirúrgicas \\
\hline & $\begin{array}{l}\text { Unidade } 18 \text { - Cuidado à criança/adolescente } \\
\text { hospitalizada }\end{array}$ & $\begin{array}{l}\text { Cuidados à criança/adolescente em situações } \\
\text { clínicas/cirúrgicas }\end{array}$ \\
\hline & Unidade 19 - Interação comunitária*: & \\
\hline \multirow[t]{3}{*}{$\begin{array}{r}4^{\circ} \\
\text { serie } \\
\end{array}$} & Unidade 20 - Estágio supervisionado em & \\
\hline & $\begin{array}{l}\text { Unidade } 21 \text { - Estágio supervisionado em } \\
\text { serviços hospitalares** }\end{array}$ & \\
\hline & Unidade 22 - Interação comunitária" & \\
\hline
\end{tabular}

\footnotetext{
* As Unidades Educacionais 6, 13, 19 e 22 (Interação Comunitária) são desenvolvidas em Unidades Básicas de Saúde, com alunos dos cursos de Enfermagem e Medicina, em nível crescente de complexidade e têm como finalidade realizar o diagnóstico de saúde de uma área de abrangência, planejar ações de saúde, implementa-las e avaliá-las.

** As Unidades Educacionais 20 e 21 (Estágio Supervisionado) possibilitam aos estudantes vivenciar o trabalho do enfermeiro, respectivamente, em serviços extra-hospitalares e hospitalares
} 
A Unidade Educacional Saúde do Adulto e do Idoso tem como propósito estudar o papel do adulto e do idoso na sociedade, as políticas sociais e a organização dos serviços para o seu atendimento, bem como a compreensão do processo saúde doença nas dimensões bio-psico-sócio-culturais (5)

Os desempenhos a serem desenvolvidos nessa Unidade Educacional são prestar cuidados de enfermagem ao adulto e idoso fumante, ao usuário de álcool, ao portador de alterações da integridade cutânea, ao portador de hipertensão arterial, diabetes mellitus, tuberculose, hanseníase, e ao portador de distúrbios mentais. Além disso, trabalha-se também os desempenhos que já vinham sendo realizados em unidades anteriores como: utilizar a metodologia científica, trabalho com grupo e em grupo, utilizar precaução padrão e avaliar o estado de saúde através do método clínico.

Para a elaboração da Unidade Educacional contou-se com a participação e o envolvimento dos docentes que, no modelo de organização curricular anterior, pertenciam às disciplinas de Patologia, Enfermagem em Saúde Coletiva, Enfermagem Clínica, Enfermagem em Saúde Mental/Psiquiátrica, Psicologia, Ética e Bioética, Farmacologia e Microbiologia.

Para o presente relato, elegeu-se o recorte do conhecimento feito para o ensino dos cuidados de enfermagem ao adulto e idoso portador de alterações da integridade cutânea, uma vez que nessa área o conhecimento vem renovando-se com muita freqüência, exigindo do profissional a busca constante do conhecimento, além de tratar-se de um tema que exige atuação ativa do enfermeiro, sendo, inclusive, objeto de cursos de especialização.

A cicatrização de feridas é um processo complexo que envolve diversos estágios fisiológicos interdependentes e simultâneos, os quais devem ser conhecidos pelo enfermeiro: a inflamação, a reconstrução, a epitelização e a maturação. O curativo tem como objetivo manter ambiente adequado para a cicatrização e deve constar de: a) avaliação do portador da lesão, segundo uma abordagem holística; b) avaliação da lesão quanto ao seu grau de perda tissular, fase da cicatrização e tipo de ferida; c) limpeza da lesão e d) cobertura (6).

A seqüência de atividades que tratou desta questão encontra-se no Quadro 2 e, para o seu desenvolvimento, considerou-se que o aluno já possuía conhecimento sobre histologia da pele, conteúdo já abordado na Unidade 7 , que trata da avaliação do estado de saúde do indivíduo.

Relacionaram-se, então, os desempenhos a serem atingidos pelos alunos e que, uma vez elaborados, serviram de guia para a construção da seqüência de atividades. Entende-se por desempenho uma ação que, para sua realização, mobiliza atributos de ordem cognitiva, afetiva e psicomotora. Esses desempenhos são apresentados como se segue:

\section{DESEMPENHOS}

\section{PRESTA CUIDADOS DE ENFERMAGEM AO ADULTO E AO IDOSO COM ALTERAÇÃO DA INTEGRIDADE CUTÂNEA}

- Conhece a microbiota da pele;

- Identifica os tipos de alterações da integridade da pele;

- Conhece e identifica as fases do processo de cicatrização;

- Conhece e identifica as fases do processo infeccioso;

- Conhece os princípios de assepsia e anti-sepsia;

- Conhece os mecanismos de ação dos anti-sépticos e dos medicamentos tópicos utilizados em curativo;

- Conhece as indicações e mecanismos de ação dos principais produtos utilizados no tratamento de feridas (papaína, hidrocolóide, hidrogel, alginato de cálcio, membranas ou filmes semi-permeáveis, Ácidos Graxos Essenciais);

- Lava as mãos antes e após a realização do curativo;

- Avalia a lesão e indica o curativo apropriado;

- Seleciona o material;

- Avalia o material (quanto a integridade do acondicionamento, validade da esterilização e das soluções e medicações);

- Comunica-se com o indivíduo portador de alteração da integridade da pele de forma clara e respeitosa;

- Realiza a técnica de curativo respeitando os principios de assepsia:

- abre o material de curativo sem contaminá-lo;

- retira o curativo sujo com luvas de procedimento ou com pinça dente de rato e pinça kelly;

- troca as luvas ou despreza as pinças utilizadas em local apropriado;

- realiza a limpeza da ferida com jato de soro fisiológico;

- abre pacotes de gazes fora do campo estéril;

- executa a manipulação do material sem cruzar o campo;

- seca a pele ao redor da ferida pressionando a gaze seca delicadamente;

- oclui a ferida sempre que necessário;

- despreza o material contaminado em local apropriado;

- mantém a ordem do ambiente. 
Quadro 2: Seqüência de atividades

Conceito Chave: Cuidados de Enfermagem do adulto e ao idoso com alteração na integridade cutânea

\section{Seqüência de Atividades}

1. A partir da experiência de assistência ao portador de alteração da integridade cutânea, discuta em pequenos grupos:

a) tipo de lesões e características da lesão;

b) ações necessárias para cuidados com as lesões observadas;

c) implicações psico-sociais para o portador da alteração da integridade cutânea;

d) o que acontece com a ferida desde o momento em que ela surge até quando ela desaparece. Sintetizar os dados.

2. Apresente em plenária.

3. Realize leitura de material bibliográfico sobre: microbiota da pele, tipos de alterações da integridade da pele, fases do processo de cicatrização e fases do processo infeccioso.

4. Participe de exposição dialogada sobre os itens da atividade 3.

5. Retome os dados das atividades 1 e 2 e analise o tipo de lesão, localização, aparência da pele ao redor, presença de exsudato, substâncias utilizadas para fazer o curativo e a forma com que o curativo é feito.

6. Sintetize e apresente em plenária os dados da atividade 5.

7. Realize leitura de material bibliográfico sobre: evolução dos curativos através dos tempos, princípios gerais dos cuidados com feridas, classificação, formato, tamanho, localização, aparência, presença de exsudatos nas feridas, características da pele ao redor da ferida, importância da. lavagem das mãos, privacidade e horário. Finalidade do curativo, tipos de curativo e curativo ideal. Substâncias utilizadas para realização de curativo.

8. Sintetize os dados da atividade 7 e participe de exposição dialogada.

9. Assista à demonstração da técnica de curativo.

10. Execute a técnica de curativo.

\section{Orientação para o Professor}

1. Dividir os estudantes em pequenos grupos e estimular a. discussão.

2. Coordenar a plenária destacando: classificação, profundidade, formato, localização das feridas, presença de secreção e processo de cicatrização.

3. Orientar o grupo para a busca de material bibliográfico sobre o assunto.

4. Coordenar a atividade e convidar professores especialistas de fisiologia, microbioologia e patologia e psicologia

5. Apoiar a atividade.

6. Coordenar a atividade destacando: classificação das feridas, presença de exsudato, substâncias e formas utilizadas nos cuidados das feridas.

7. Orientar o grupo para a busca de material bibliográfico e coordenar a atividade.

8. Coordenar a atividade e convidar professor especialista e professor de farmacologia.

9. Dividir os estudantes em pequenos grupos e realizar a demonstração da técnica de curativo destacando os principios de assepsia e antissepsia.

10. Supervisionar o aluno na técnica de realização do curativo em laboratório e em campo de estágio. 
A avaliação, nesse processo, leva em consideração o desempenho do estudante, constituindo-se em um ato dinâmico de natureza processual a que se atribui os conceitos satisfatório e insatisfatório.

\section{CONSIDERAÇÕES FINAIS}

Trabalhar com um currículo integrado e com a metodologia problematizadora representa um avanço e, acima de tudo, um desafio.

Tal proposta encontra-se no seu terceiro ano de implantação e tem esbarrado em algumas dificuldades, entre elas, a formação dos docentes, segundo o modelo tradicional, a qual não estimula a criatividade, permitindo a nossa adequação apenas ao que estava estabelecido, com poucas possibilidades de transformação da realidade.

Também podemos assinalar que, como todo o processo de planejamento e implementação das Unidades Educacionais se dá coletivamente, embora isso enriqueça a produção, o fato exige dos docentes habilidades que ainda necessitam ser aprimoradas como, por exemplo, o diálogo entre diversas disciplinas, seja do ciclo básico ou específicas da área da enfermagem e o exercício do respeito às opiniões divergentes, entre outras.

Com relação ao recorte de conhecimento, também nos deparamos com alguns problemas. Como foi assinalado anteriormente, para que haja aprendizagem significativa é necessária a articulação entre o conhecimento prévio dos estudantes com os novos assuntos apresentados. Esses, além de guardarem uma seqüência lógica entre si, também devem ser contextualizados, ou seja, articulados com a realidade, partindo do concreto para o abstrato. Nesse ponto, observamos que, muitas vezes, incluímos um volume excessivo de conteúdo, com muitos textos para serem trabalhados num curto espaço de tempo. Tal situação gera ansiedade nos docentes e nos estudantes, além de comprometer a problematização.

Acreditamos que tais problemas sejam superáveis e já estamos nos movimentando para isso através de discussões sistemáticas sobre os mesmos, assessorias de profissionais especializados e capacitação docente.

Consideramos que este caminho seja uma alternativa viável - não a única -- para darmos conta do processo ensino-aprendizagem no contexto complexo do mundo atual, em que o conhecimento considerado válido hoje, não mais o será dentro de alguns anos. Nesse caso, torna-se importante e necessário aprender a aprender e não apenas reter informações.
A experiência relatada neste trabalho, que trata do ensino da assistência de enfermagem ao portador de alteração da integridade cutânea, mostrou a importância dos temas de estudo emergirem das situações práticas vividas pelos estudantes, além da busca de colocá-lo no centro do processo educativo.

\section{REFERÊNCIAS BIBLIOGRÁFICAS}

(1) Kisil M, Chaves M, editores. Programa UNI: uma nova iniciativa na educação dos profissionais de saúde. Battle Creek: Fundação W. K. Kellogg; 1994. cap. 1-2, p.1-23.

(2) Davini MC. Currículo integrado. In: Brasil. Ministério da Saúde. Coordenação Geral de Recursos Humanos para o SUS. Capacitação pedagógica para instrutor/supervisor área da saúde. Brasília; 1994. p.39-49.

(3) Chirelli MQ, coordenadora. Introdução ao curso de enfermagem. Marília: Faculdade de Medicina de Marília; 1999.

(4) Diaz Bordenave J, Pereira AM. Estratégias de ensino aprendizagem. 13․ ed. Petropólis: Vozes; 1993.

(5) Marin MJS, coordenadora. Saúde do adulto e do idoso: $2^{a}$ série enfermagem - Unidade 10/12. Marilia: Faculdade de Medicina de Marília; 1999.

(6) Dealy C. Cuidando de feridas. São Paulo: Atheneu; 1996.
Artigo recebido em 24/04/00
Artigo aprovado em $19 / 02 / 03$ 